\title{
Identification of suspected fatal adverse drug reactions by paediatricians: a UK surveillance study
}

\author{
K Cheng, ${ }^{1}$ S Masters, ${ }^{1}$ T Stephenson, ${ }^{2}$ R Cooke, ${ }^{3}$ R Ferner, ${ }^{4}$ M Ashworth, ${ }^{5}$ A J Nunn ${ }^{5}$
}

\begin{abstract}
${ }^{1}$ Medicines and Healthcare products Regulatory Agency, London, UK; ${ }^{2}$ Centre for Reproduction and Early Life, Queen's Medical Centre, Nottingham, UK; ${ }^{3}$ Neonatal Unit, Liverpool Women's Hospital, Liverpool, UK; ${ }^{4}$ City Hospital, Birmingham, UK;

${ }^{5}$ Alder Hey Children's Hospital, Liverpool, UK
\end{abstract}

Correspondence to:

Professor Terence Stephenson Centre for Reproduction and

Early Life, Academic Division of Child Health, School of Human Development, Queen's Medical Centre, Nottingham NG7 2UH, England; terence.stephenson@ nottingham.ac.uk

Accepted 12 June 2007 Published Online First 22 June 2007

\section{ABSTRACT}

This British Paediatric Surveillance Unit (BPSU) study on adverse drug reactions (ADRs) in children was initiated because of concern that there might be under-reporting of serious ADRs in children using the yellow card scheme. We aimed to quantify the frequency of fatal ADRs in children under the age of 16 years in the United Kingdom and Ireland. The surveillance period ran for 13 months from June 2002 to June 2003, inclusive, and approximately 2000 cards were sent out monthly by the BPSU to consultant paediatricians in the United Kingdom and Ireland. In total, seven reports meeting the study criteria were received. Causality assessment was undertaken by an independent expert panel using formal, published criteria. In two of the deaths, the panel did not reach consensus and causality assessments varied from possible to certain. Five of the seven deaths were unanimously thought to be unlikely to be causally related to the index drug. Overall this study does not provide evidence of a major public-health concern relating to fatal ADRs in children. However, the limitations of the study mean that some fatal ADRs may have been unrecognised or unreported.

Many drugs are prescribed for children outside of their licence ("off-label"), ${ }^{1-3}$ including drugs not licensed for a certain age group, for a particular route or for a specific disease. The UK spontaneous reporting system, the yellow card scheme, is a key source of pharmacovigilance data, and it receives reports from doctors, dentists, coroners, pharmacists and nurses. However, spontaneous reporting under-reports ADRs. ${ }^{4}$ Under-reporting may be compounded by fears of litigation following unlicensed prescribing, and ADRs may be more likely with unlicensed drugs. ${ }^{5}$

We are not aware of any studies of the extent of fatalities following ADRs in UK children. A metaanalysis of 39 studies in US hospitals estimated that 2216000 patients, predominantly adults, experienced a serious ADR during 1994, and 106000 died. ${ }^{6}$ Risk of fatality increased with the number of drug exposures and age and length of hospital stay, which suggests a lower risk in children. Of more than 500000 adverse event reports to the US FDA (including from the public) from 1997 to 2000, 7111 events were in children aged under 2 years and included 243 deaths per year associated with drug therapy. Of these, on average, 204 were infants under 1 year including 100 deaths in neonates. ${ }^{7}$ Twenty-four percent of all adverse events were associated with maternal drug therapy during pregnancy or breast feeding and, when excluded, only 17 drugs or biological products were suspected in $54 \%$ of all serious and fatal adverse events. These included two prophylactics against respiratory syncytial virus, six antibiotics and two analgesics. The limitation of this study was that no causality assessment was undertaken.

The British Paediatric Surveillance Unit (BPSU) operates an active surveillance mechanism (the "orange card" scheme), and every month all consultant paediatricians in the United Kingdom and Ireland who are members of the Royal College of Paediatrics and Child Health are mailed a report. Ninety-two percent of cards sent out were returned during the period of surveillance. ${ }^{8}$ This paper reports a 1-year BPSU study of fatal ADRs in children.

\section{METHODS}

Surveillance was from June 2002 to June 2003 Approximately 2000 orange cards are sent out each month.

A case is defined as a suspected fatal ADR in a child under 16 years of age in the previous month.

The Medicines and Healthcare products Regulatory Agency (MHRA) obtained anonymised case details through a questionnaire sent to the reporter. There was no contact with the family or any other health professional. Causality assessments were undertaken independently by an expert panel, which included specialists in paediatric pathology, paediatric pharmacy, neonatology, paediatrics and pharmacovigilance.

$\mathrm{ADR}$ was defined as "an appreciably harmful or unpleasant reaction resulting from an intervention related to the use of a medicinal product, which predicts hazard from future administration and warrants prevention or specific treatment, or alteration of the dosage regimen, or withdrawal of the product". Causality was classified as certain, probable/likely, possible, unlikely conditional/ unclassified or unassessable/unclassifiable ${ }^{9}$ on the basis of the temporal relationship; concurrent disease or other drugs; and the results of dechallenge/rechallenge (if available).

\section{RESULTS}

From 1 June 2002 to 30 June 2003, 16 suspected fatal ADRs in children under 16 years were notified. Of these 16, two of the cases were reported by three different reporters and one case was reported twice by the same reporter. In two cases, the reporter subsequently denied the report and one was outside of the time frame. One questionnaire was not returned, despite repeated requests. Therefore, seven reports met the study criteria. 


\section{Case 1}

An ex-preterm infant started persistent crying $3 \mathrm{~h}$ after being given thyroxine $7.5 \mu \mathrm{g}$ for congenital hypothyroidism (dose $5 \mu \mathrm{g} / \mathrm{kg}$, consistent with Medicines for Children $\left.^{10}\right)$. Progressive bradycardia developed $5 \mathrm{~h}$ after thyroxine was administered followed by cardiac arrest. Post-mortem results showed bronchopneumonia.

\section{Panel discussion}

There was a reasonable timeframe for absorption but not for pharmacological action of thyroxine. Thyroxine causes tachycardia but bradycardia may have been the terminal event. Pneumonia was not consistent with a thyroxine ADR. All panel members independently assessed causality as unlikely.

\section{Case 2}

A teenager with repaired congenital heart disease developed liver failure 22 days after starting enalapril $5 \mathrm{mg}$ for heart failure. The patient died 6 days later. Post-mortem liver biopsy showed severe acute damage without evidence of chronic liver disease. The reported differential diagnosis included acute viral hepatitis and toxic/drug-related injury.

\section{Panel discussion}

Enalapril is not licensed for use in children, and hepatic failure is a recognised ADR. ${ }^{11}$ The liver biopsy demonstrated eosinophils, suggesting drug-related damage. An onset time of 1-8 weeks has previously been reported for acute hepatitis associated with captopril. ${ }^{12}$ Two members assessed causality as possible, two as probable and one as certain.

\section{Case 3}

An ex-preterm infant developed fatal exacerbation of chronic lung disease 3 days after immunisation with Prevenar (streptococcal pneumoniae conjugate) vaccine, meningococcal $C$ vaccine and a study vaccine DT5aP-Hib-IPV (combined diphtheria, tetanus, acellular pertussis, haemophilus-b and inactivated polio).

\section{Panel discussion}

Apnoea has been reported in preterm infants in the 3 days following DTP (diphtheria, tetanus and pertussis) and Hib immunisation. ${ }^{13} 14$ However, the slow deterioration was more likely to be caused by pulmonary hypertension. An immunological response would be expected sooner or later. Prevenar is licensed for use in children over 2 months old. All panel members independently assessed causality as unlikely.

\section{Case 4}

A teenager had nasal packing performed under general anaesthesic (isoflurane, suxamethonium, fentanyl and propofol; all licenced for children). One-hour postoperatively, following self-extubation, the patient had a cardiorespiratory arrest. Postmortem liver histology showed acute central zonal necrosis and appearances thought due to isoflurane reaction.

\section{Panel discussion}

The panel considered the arrest to be caused by upper airway obstruction, not isofluorane. Liver histology showed ischaemic necrosis rather than drug reaction. The patient had not previously undergone anaesthesia. Isoflurane can produce hepatic injury very rarely. All panel members independently assessed causality as unlikely.

\section{Case 5}

A primary-school child with a developmental delay and seizures presented with vomiting and drowsiness 4 months after starting sodium valproate $280 \mathrm{mg}$ twice a day. The child died of acute pancreatitis and liver failure.

\section{Panel discussion}

Pancreatitis and hepatic failure are recognised ADRs of sodium valproate. ${ }^{15}$ The timing and pharmacological pattern were considered to be plausible and a fatty-acid oxidation disorder had been eliminated. One member assessed causality as possible, two as probable and two as certain.

\section{Case 6}

A newborn baby arrested $10 \mathrm{~h}$ after being treated with zidovudine $4 \mathrm{mg} / \mathrm{kg}$ (recommended dose $2 \mathrm{mg} / \mathrm{kg}$ every $6 \mathrm{~h}^{16}$ ). Her HIV-positive mother took zidovudine, lamivudine and nevirapine in pregnancy and then changed to abacavir, lamivudine, zidovudine and co-trimoxazole. The baby died 1 week later. Muscle biopsy ante-mortem showed normal respiratory-chain enzyme activity.

\section{Panel discussion}

The clinical picture was not consistent with anaphylaxis. All panel members independently assessed causality as unlikely.

\section{Case 7}

A young infant arrested 1 day after immunisation with diphtheria/tetanus/pertussis, (DTP), haemophilus-b, meningococcal $\mathrm{C}$ and oral polio vaccines. The infant had developed difficulty in feeding and had been irritable $6 \mathrm{~h}$ previously. Postmortem results showed haemophagocytosis in the spleen and bone marrow (responsible for the low haemoglobin $4.5 \mathrm{~g} / \mathrm{dl}$ ). The anaemia had induced cardiac failure.

\section{Panel discussion}

The timing and pharmacological pattern in association with the vaccine was not thought to be plausible. All panel members independently assessed causality as unlikely.

\section{DISCUSSION}

Seven valid suspected fatal ADR reports were received over 13 months. Five were thought to be unrelated to the index drug. In two, the independent panel did not reach consensus. Two of these seven cases were also reported to the yellow card scheme. During the same period there were an additional 16 reports of ADRs with a fatal outcome in children under 16 years reported through the yellow card scheme. These reports were of varying quality and it is not possible to compare these with those received through the BPSU. Over the same 13-month period, in England and Wales, there were 5458 deaths in children aged under 18 (4633 excluding accidents, cancer and self-poisoning). The number of death certificates citing $\mathrm{ADR}$ as a contributing factor was $14 .{ }^{17}$ Again, the anonymous nature of the data set means that we cannot compare these.

As the response rate to the BPSU scheme is high, approximately $92 \%$, this study suggests that the true frequency of fatal ADRs in children appears to be low. However, even wellrecognised, severe ADRs are under-reported. For example, only $4 \%$ of known cases of toxic epidermal necrolysis (almost exclusively due to drug exposure) are reported..$^{18}$ Furthermore, our study had limitations. Firstly, it is possible that ADRs with a fatal outcome were under-recognised because they tend to 
occur in sick children receiving multiple drugs. Moreover, there may have been a reluctance to report, even in an anonymised way, deaths thought to be due to off-label or unlicensed prescribing, although such prescribing is legal in the United Kingdom. Surveillance was restricted to paediatricians. Other schemes extend reporting to other professionals, the lay public and the pharmaceutical industry. This is a possible reason for the significantly higher suspected numbers from the United States, ${ }^{7}$ where a number of different routes were available for reporting. Although significant prescribing for children occurs in primary care, most child deaths would come to the attention of hospitals.

Overall this study does not provide evidence of a major public health concern relating to fatal ADRs in children.

Acknowledgements: The standard fee for conducting the BPSU study was paid to the RCPCH Research Division by the UK Medicines Controls Agency (now MHRA).

Competing interests: Dr Cheng and Mr Masters were employed by the Medicines and Healthcare products Regulatory Agency, and Professor Stephenson was a member of the UK Committee on Safety of Medicines when the study was conducted.

Ethics approval: Ethical approval was granted by the Multicentre Research Ethics Committee for London.

Patient consent: Informed consent was obtained for the publication of the case details described in this report.

\section{REFERENCES}

1. Turner S, Longworth A, Nunn AJ, et al. Unlicensed and off label drug use in paediatric wards: prospective study. BMJ 1998;316:343-5.

2. Conroy S, Choonara I, Impicciatore P, et al. Survey of unlicensed and off label drug use in paediatric wards in European countries. BMJ 2000;320:79-82.
3. Conroy S, Mclntyre J, Choonara I. Unlicensed and off label drug use in neonates. Arch Dis Child Fetal Neonatal Ed 1999;80:F142-5.

4. Inman WHW. Study of fatal bone marrow depression with special reference to phenylbutazone and oxyphenbutazone. BMJ 1977:1:1500-5.

5. Turner S, Nunn AJ, Fielding K, et al. Adverse drug reactions to unlicensed and off label drugs on paediatric wards: a prospective study. Acta Paediatr 1999:88:965-8.

6. Lazarou J, Pomeranz BH, Corey PN. Incidence of adverse drug reactions in hospitalized patients: a meta-analysis of prospective studies. JAMA 1998;279:12001205.

7. Moore TJ, Weiss SR, Kaplan S, et al. Reported adverse drug events in infants and children under 2 years of age. Pediatrics 2002;110:e53.

8. British Paediatric Surveillance Unit. Annual report 2002-2003. London: Royal College of Paediatrics and Child Health, 2003.

9. Edwards IR, Aronson JK. Adverse drug reactions: definitions, diagnosis and management. Lancet 2000;356:1255-9.

10. Royal College of Paediatrics and Child Health and the Neonatal and Paediatric Pharmacists Group. Medicines for children. London: Royal College of Paediatrics and Child Health,1999.

11. Summary of Product Characteristics: Innovace, Merck Sharp and Dohme.

12. Davis DM. Textbook of adverse drug reactions. 4th edn. Oxford: Oxford University Press, 1991.

13. Sanchez PJ, Laptook AR, Fisher $L$, et al. Apnea after immunisation. J Pediatr 1997:130:746-51.

14. Botham SJ, Isaacs D, Henderson-Smart DJ. Incidence of apnoea and bradycardia in preterm infants following DTPw and Hib immunization: a prospective study. J Paediatr Child Health 1997;33:418-21.

15. British National Formulary. London: Pharmaceutical Press, 2003.

16. Glaxo Smith Kline. Summary of product characteristics: Retrovir. Uxbridge: Glaxo Smith Kline.

17. Office for National Statistics: unpublished data. If this is still unpublished that it will need to be noted in the text as unpublished. If it has since been published please provide the name of the report, date, author, publisher and location and perhaps a URL.

18. Mittmann N, Knowles SR, Gomez M, et al. Evaluation of the extent of underreporting of serious adverse drug reactions. The case of toxic epidermal necrolysis. Drug Safety 2004;27:477-7.

\section{Submit an eLetter, and join the debate}

eLetters are a fast and convenient way to register your opinion on topical and contentious medical issues. You can find the "submit a response" link alongside the abstract, full text and PDF versions of all our articles. We aim to publish swiftly, and your comments will be emailed directly to the author of the original article to allow them to respond. eLetters are a great way of participating in important clinical debates, so make sure your voice is heard. 